\title{
Self-reported association and determinants of KAP on food safety and hygiene among Private University Students in Kedah state, Malaysia
}

\begin{abstract}
Objective: To identify the association, correlation and determinants of knowledge, attitude, and perception (KAP) on food safety and hygiene (FS\&H) among private University students.

Method: A cross sectional study, using pre-validated, 36-item questionnaire was conducted in a private University campus involving students through self-administered survey forms. The completed questionnaires were retrieved and analysed using SPSS version 23. The association, correlations and determinants of socio-demographic variables were analysed using KAP scores.

Result: Among the 869 respondents, the total median(IQR) knowledge score was found to be 11(3), whereas the attitude score was found to be 28(3), perception score was 54(10) and the total median KAP scores was found to be 92(11). The median total KAP scores ranged between 48 and 104, from poor to good. The total knowledge score was found to be moderate (49\%), whereas the total attitude, perception and KAP scores were found to be positive $(87 \%),(93 \%)$ and $(90 \%)$ respectively. The study found significant association between KAP scores and socio-demographic variables $(\mathrm{p}<.05)$. The correlation between total knowledge, attitude and perception scores showed significantly strong positive correlations $[\mathrm{r}(869)=902, \mathrm{p}<.001]$ with KAP scores. It was found gender and types of diet were statistically significant determinants among socio-demographic variables using simple linear regression. $[\mathrm{F}(8,860)=5.23, \mathrm{p}<.001]$.

Conclusion: Majority of respondents showed moderate knowledge with positive attitude, and perception towards all domains with strong positive correlations. Continuous education is necessary to increase the awareness among young adults as in the near future; they will be directly handling food and play an important role to help maintain safe and hygienic food habits at home and community.
\end{abstract}

Keywords: food safety and hygiene, knowledge, attitude, perception, association, correlation, determinants, public health, consumption, diseases
Volume 5 Issue 5 - 2018

\author{
Abdul Nazer Ali,' Angeline Francis William,' \\ Sunil K. Prajapati,' Nazer Zulfikar Ahmed² \\ 'Faculty of pharmacy,AIMST University, Malaysia \\ ${ }^{2}$ Cognizant Technology Solutions India Private Limited, \\ Hyderabad, India
}

Correspondence: Abdul Nazer Ali, Faculty of pharmacy, AIMST University, Semeling, 08I00 Bedong,

Kedah Darul Aman, Malaysia,

Email abdul.nazeralil6@gmail.com

Received: September 20,2018 | Published: October 02, 2018
Abbreviations: CDC; centre for disease control, CI; confidence interval, IQR; interquartile range, FS\&H; food safety and hygiene, $\mathrm{KAP}$; knowledge attitude and perception, $\mathrm{MOH}$; ministry of health, OR; odds ratio, WHO; world health organization

\section{Introduction}

Food safety and hygiene (FS\&H) is important in defining global public health, as millions suffer or die consuming contaminated food due to food-borne diseases or illnesses and many are hospitalized. ${ }^{1-3}$ World Health Organization (WHO), (2007) identified food-borne disease outbreaks and epidemics as major global health threats in the twenty-first century, among both, developed and developing countries. $^{4}$

Global epidemiological data indicate, improper food processing practices among consumers' attribute significant risk for foodborne diseases which can be avoided if food safety procedures are implemented from food production to consumption., ${ }^{1,3}$ Poor food handling practices lead to potential cross-contaminations and subsequent food poisoning. ${ }^{5}$ Thus, WHO assists in promoting safe food handling through systematic disease prevention and education programs directed to food handlers, including consumers' ${ }^{6}$ It is known that education for consumers is one of the main interventions to increase the knowledge on food safety. However, based on marketing experts from United States, educational programs directed to "all" will only meet the needs of few. ${ }^{7-9}$ According to Osaili et al., (2011), female college students had inadequate knowledge towards prevention of food-borne illnesses and few other studies highlight poor adherence to food handling practices among university students. ${ }^{10,11}$ Although limited information about associated factors prevail among Malaysian youth, Mullan and Wong, (2010) reported increasing the knowledge level can change behaviour, referring to theory of planned behaviour, which demonstrated people act in accordance with their intentions, and intentions are influenced by attitudes. ${ }^{12,13}$

Based on the problem, it is important to evaluate the student's level of knowledge, which will determine their perception and attitude which subsequently transform into their behaviour. It is important to identify the socio-demographic factors associated with KAP on FS\&H. This study outcome may pave necessary intervention opportunities to consider and enhance FS\&H and plan appropriate strategies to reduce prevalence of food borne diseases among the student community and at large the nation through community.

\section{Outcome measures}

The main outcome measure of this study was to identify 
the association, correlation and determinants (predictive sociodemographic factors) of KAP on FS\&H among private University students in Kedah state, Malaysia.

\section{Materials and methods}

Study Design, Site and Target Population

A cross sectional study among private university students in campus belonging to various educational backgrounds (Medicine, Dentistry, Pharmacy, Biotechnology, Business, Physiotherapy, Diploma and Foundation studies) was done in Kedah State, Malaysia. The study was conducted between March, 2018 and May, 2018. The studies inclusion criteria included: both male and female students of various disciplines willing to participate and signed the informed consent form. Those not willing, incomplete survey forms, those who did not sign the informed consent and those involved in pilot study were excluded.

\section{Sample size calculation}

Total number of students in the University according to University portal (UniRankPortal) was utilized as total student's population from which the sample size was calculated using an automated Raosoft sample size calculator. ${ }^{14,15}$ The estimated sample size was calculated at $95 \% \mathrm{CI}, 5 \%$ margin of error with $50 \%$ response distribution and the required sample size was 385 . A $10 \%$ margin for drop-outs was added and rounded off to get a final recommended sample of $\mathrm{N}=420$.

\section{Development of study tool (Questionnaire)}

The questionnaire consists of four sections, testing knowledge, attitude and perception about FS\&H including socio-demographic profile of participants. The questions for the study were adapted from various literatures and official websites like $\mathrm{CDC}, \mathrm{WHO}, \mathrm{MOH}$ etc. The questions / statements were modified to suit the objectives of the present study. Questions pertaining to knowledge included dining place cleanliness, personal hygiene, food processing, food contamination, its identification, signs and symptoms of food poisoning etc. ${ }^{16,17}$ Statements pertaining to attitude included hand washing techniques/ habits, disposal of food waste, maintenance of rubbish bin, stray /pet animals in dining areas etc. ${ }^{18,19}$ Perception based statements include food services, responsibilities of food handlers, sanitation of cooking and dining areas, personal hygiene of food handlers, tidiness of food service/dining area etc..$^{17,19}$

\section{Validation of questionnaire}

The content validation was conducted in stages among five academicians from faculty of Pharmacy, two persons from university catering committee and a supervisor of university cafeteria. All recommendations/suggestions from the review personnel were considered. The initial survey questionnaire was designed containing 20 knowledge items, 15:15 items to assess attitude and perception respectively regarding FS\&H (Total 50 items). Five items from knowledge domain, three from attitude and three pertaining to perception domains were eliminated at the content validation stage as per panel's recommendation. Thus, a 39 item questionnaire was arrived. After the content validation was satisfactory, the questionnaire was subjected to face validated among potential respondents $(\mathrm{N}=30)$. The responses were analysed to validate the degree of understanding within the group and modified wherever necessary to reflect the pre-testing results. Finally, the reliability of the 39 items ad hoc questionnaire was tested using Cronbach's alpha coefficient for internal consistency. Questionnaire was anonymous and selfadministered with close-ended type ("Yes", "No" or "Don't No") or multiple choice questions with one correct answer to test knowledge domain, a three point Likert scale to measure attitude and five point Likert scale to measure perception. One item from knowledge and two items from attitude domains showed negative corrected itemtotal correlation were removed. The Cronbach's alpha test for internal consistency of the questionnaire was .882 showing good reliability. ${ }^{20,21}$

The final 36 item KAP survey questionnaire on FS\&H consisted of four sections: 1) socio-demographic details such as age, gender, race, etc; 2) 14 knowledge items; 3) 10 attitude items; and, 4) 12 perception items.

\section{Modality of obtaining response}

Informed consent form was signed before distribution of survey forms. The survey questionnaires were distributed in classroom setting and the completed questionnaires were retrieved and compiled for data analysis. The average time taken to complete the questionnaire was approximately 20 minutes.

\section{Scoring grades and scoring pattern}

The scoring grades attributed to each domain and overall, were adopted from the Original Bloom's cut off grade, score of $80-100 \%$ correct response as good, $60-79 \%$ as satisfactory and score $<60 \%$ as poor. ${ }^{22-25}$

\section{Ethical consideration}

A research proposal along with the study instruments and informed consent form were submitted to the Institutional Review Board (IRB), AIMST University Human Ethical Committee for approval. Informed consent form was obtained from respondents before the survey questionnaire were distributed. Participation in the study was completely voluntary and was allowed to withdraw from the study at any point of time. High level of confidentiality was assured and maintained at all levels with the handling of information collected.

\section{Statistical analysis of data}

The survey data analysed using Statistical Package for Social Sciences 'SPSS version-23' for windows. The categorical variables were illustrated using descriptive statistics for frequency, percentage, median and IQR and p-values computed using Pearson's Chi Square test. A p value $<.05$ was considered significant. Inferential statistics were performed using Spearman's correlation and simple linear regression for predictive factors or determinants.

\section{Results}

\section{Respondent's socio-demographic data}

Among the 1100 questionnaires distributed to the university students, $869(79 \%)$ valid questionnaires were retrieved and the dropouts were mainly due to incomplete questionnaires or unwilling to participate. Most of the respondents (56\%) were aged 21 to 23 years, three-fourth females, Chinese and with degree education of whom, a little more than one-fourth were pharmacy background and year three education. More than three-fourth of respondents was on nonvegetarian diet and urban located. (Table 1) 
Table I Socio-demographic data of respondents $(\mathrm{N}=896)$

\begin{tabular}{|c|c|c|}
\hline Variables & $\mathbf{N}$ & Percentage \\
\hline \multicolumn{3}{|l|}{ Age } \\
\hline $18-20$ & 329 & 38 \\
\hline $21-23$ & 487 & 56 \\
\hline $24-26$ & 53 & 6 \\
\hline \multicolumn{3}{|l|}{ Gender } \\
\hline Male & 219 & 25 \\
\hline Female & 650 & 75 \\
\hline \multicolumn{3}{|l|}{ Race } \\
\hline Malay & 45 & 5 \\
\hline Indian & 176 & 20 \\
\hline Chinese & 648 & 75 \\
\hline \multicolumn{3}{|l|}{ Education } \\
\hline Foundation diploma in nursing & 203 & 23 \\
\hline Degree & 667 & 77 \\
\hline \multicolumn{3}{|l|}{ Field of study } \\
\hline Foundation \& diploma & 75 & 9 \\
\hline Medicine & $13 \mid$ & 15 \\
\hline Dentistry & 170 & 20 \\
\hline Pharmacy & 215 & 24 \\
\hline Physiotherapy & 41 & 5 \\
\hline Business & 167 & 19 \\
\hline Biotechnology & 70 & 8 \\
\hline \multicolumn{3}{|l|}{ Years of study } \\
\hline Year I & 337 & 39 \\
\hline Year 2 & 164 & 19 \\
\hline Year 3 & 227 & 26 \\
\hline Year 4 & $|4|$ & 16 \\
\hline \multicolumn{3}{|l|}{ Type of diet } \\
\hline Vegetarian & 34 & 4 \\
\hline Non vegetarian & 835 & 96 \\
\hline \multicolumn{3}{|l|}{ Location } \\
\hline Rural & 188 & 22 \\
\hline Urban & 681 & 78 \\
\hline
\end{tabular}

\section{Association of KAP scores among demographic} variables

The knowledge, attitude and perception (KAP) scores were categorised into good, moderate and poor based on original Blooms cut-off grades. Table 2 presents the results of KAP score association towards socio-demographic variables of the respondents.

\section{Association between KAP scores and demographic variables}

The median knowledge score among age category was moderate, 11(3)/14, with positive attitude $28(3) / 30$ and positive perception score, 54(10)/60. The study observed a significant association among knowledge score $[X 2(6, N=896)=15.37, p<.05]$, attitude score $[X 2$ $(6, N=869)=23.6, p<.001]$, perception score $[X 2(6, N=869)=20.84$, $p<.05]$ and age category respectively. Among Gender category, the study observed a significant association of knowledge score $[X 2(2$, $N=896)=6.14, p<.05]$, attitude score $[X 2(2, N=869)=6.52, p<.001]$ and perception score $[X 2(2, N=869)=17.51, p<.001]$ respectively. Whereas, there was no association $(p>.05)$ observed among knowledge, attitude or perception scores and race category. Among education category, the study observed a significant association only among attitude score $[X 2(2, N=869)=12.83, p<.05]$ and perception score $[X 2(2, N=869)=9.91, p<.05]$ respectively. Whereas, course of study observed a significant association of knowledge score $[X 2(2$, $N=896)=25.57, p<.05]$, attitude score $[X 2(2, N=869)=105.04, p<.001]$ and perception score $[X 2(2, N=869)=49.10, p<.001]$. Among year of study, a significant association was observed among knowledge score $[X 2(8, N=896)=40.68, p<.001]$, attitude score $[X 2(8, N=869)=39.68$, $p<.001]$ and perception score $[X 2(8, N=869)=18.40, p<.05]$. Among types of diet, the study observed a significant association in perception score $[X 2(2, N=869)=15.33, p<.001]$. There were no association between location and KAP scores (Table 2).

\section{Overall total score distribution of the respondents}

Table 3 summarizes the overall total score distribution of each domain studied. The total knowledge score was found to be moderate (49\%) with median score of 11(3), whereas the total attitude, perception and KAP scores were found to be positive (87\%), (93\%) and $(90 \%)$ and median scores of 28(3), 54(10) and 92(11) respectively. The median KAP scores ranged between 48 and 104 respectively which were poor to good.

\section{Correlation of KAP scores towards FS\&H}

Based on Spearman's rank-order test, the correlation between total knowledge score, total attitude and total perception scores was done against total KAP scores which showed significantly strong positive correlations. Table 4 depicts the knowledge score correlation between attitude, perception and total KAP scores, with a study population of $\mathrm{N}=869$. Correlation of median knowledge score, 11(3) to median of attitude score, 28(3), and to median of perception score, 54(10) was found to be $\mathrm{r}_{\mathrm{s}}(896)=.176, p<.001$ and $\mathrm{r}_{\mathrm{s}}(896)=.077, p=.024$, the median knowledge score correlation to KAP score 92(11) was found to be $r_{s}(869)=.361, p<.001$ which were positively correlated.

The correlation of median attitude score, 28(3) to median KAP score, 92(11), and median perception score, 54(10) was found to be $r_{s}(869)=.545, p<.001$ and $r_{s}(869)=.316, p<.001$ that were also positively correlated. The correlation of median perception score, 54(10) to median KAP score, 92(11) was found to be $\mathrm{r}_{\mathrm{s}}(869)=.902$, $p<.001$ which were also positively correlated.

\section{Analysis for determinants among socio-demographic factors}

Table 5 illustrates the outcome of simple linear regression analysis done to analyse the relationship between predictive socio-demographic factors (determinants) that are associated between KAP and FS\&H. Through the simple linear regression, it was found that independent variables like gender, education and types of diet were found to show statistical significance at $p<.05$ or $p<.001$ levels, inferring the total KAP was predictive. This can be seen as $[\mathrm{F}(8860)=5.237, p<.001]$. Besides that, through the unstandardised coefficient, the beta values for gender, education and type of diet were denoted as ' $\mathrm{m}$ ' for the 
equation of slope $[\mathrm{y}=\mathrm{m}(\mathrm{x})+\mathrm{c}]$. The significance of these slope were determined based on $t$ and $p$ value. Hence, in this case, the predictor or determinant (gender and types of diet) were good in predicting the dependent variables. As for education, the slope $\mathrm{B}=-.74$, is considered very close to zero, hence, education was not included in this test.

Table 2 Respondents' KAP Score distribution towards FS\&H and their socio-demographic characteristics

\begin{tabular}{|c|c|c|c|c|c|c|c|c|c|c|c|c|c|}
\hline \multirow[t]{2}{*}{$\begin{array}{l}\text { Demographic } \\
\text { Variables }\end{array}$} & \multirow[t]{2}{*}{$\begin{array}{l}N(\%) \\
N=869\end{array}$} & \multicolumn{4}{|l|}{ TKS } & \multicolumn{4}{|l|}{ TAS } & \multicolumn{4}{|l|}{ TPS } \\
\hline & & $P$ & $M$ & G & $P$ value & $N$ & \pm & $\mathrm{P}^{+}$ & $P$ value & $N$ & \pm & $\mathrm{P}^{+}$ & $P$ value \\
\hline \multicolumn{14}{|l|}{ Age } \\
\hline $18-20$ & $329(37)$ & $65(8)$ & $172(20)$ & $92(1)$ & & $6(1)$ & $22(3)$ & $30 I(35)$ & & $7(1)$ & $8(1)$ & $314(36)$ & \\
\hline $21-23$ & $487(56)$ & $76(9)$ & $23 I(27)$ & $180(21)$ & $.018^{*}$ & $18(2)$ & $62(7)$ & $407(47)$ & $<.001 *$ & $9(1)$ & $32(4)$ & $446(51)$ & $.002 *$ \\
\hline $24-26$ & $53(7)$ & $5(I)$ & $2 I(2)$ & $27(3)$ & & $6(1)$ & $2(0)$ & $4 I(5)$ & & $0(0)$ & $9(2)$ & $44(6)$ & \\
\hline \multicolumn{14}{|l|}{ Gender } \\
\hline Male & $219(25)$ & $42(5)$ & $91(10)$ & $86(10)$ & $.046^{*}$ & $17(2)$ & $19(2)$ & $18(3)$ & $<.001 *$ & $9(1)$ & $2 \mathrm{I}(2)$ & $189(22)$ & $<.00 I^{*}$ \\
\hline Female & $650(75)$ & 104(I2) & $333(38)$ & $213(25)$ & & $13(1)$ & $67(8)$ & $570(66)$ & & $7(1)$ & $28(3)$ & $615(71)$ & \\
\hline \multicolumn{14}{|l|}{ Race } \\
\hline Malay & $45(5)$ & $5(I)$ & $21(3)$ & $19(2)$ & & $0(0)$ & $2(0)$ & $43(5)$ & & $0(0)$ & $I(0)$ & $44(5)$ & \\
\hline Indian & $648(75)$ & $26(3)$ & $82(9)$ & $68(8)$ & 0.602 & $7(1)$ & $15(2)$ & $154(18)$ & 0.596 & $3(0)$ & $14(2)$ & $159(18)$ & 0.665 \\
\hline Chinese & $176(20)$ & $115(13)$ & $321(37)$ & $212(24)$ & & $23(3)$ & $69(8)$ & $556(I)$ & & $13(1)$ & $34(4)$ & $60 I(70)$ & \\
\hline \multicolumn{14}{|l|}{ Education } \\
\hline $\begin{array}{l}\text { Foundation \& } \\
\text { Diploma }\end{array}$ & $203(23)$ & $37(4)$ & $109(13)$ & $57(7)$ & 0.095 & $0(0)$ & $14(2)$ & $189(22)$ & $.002^{*}$ & $2(0)$ & $3(0)$ & $198(23)$ & $.007^{*}$ \\
\hline Degree & $666(77)$ & $109(13)$ & $315(36)$ & $242(28)$ & & $30(3)$ & $72(8)$ & $564(65)$ & & $14(2)$ & $46(5)$ & $606(70)$ & \\
\hline \multicolumn{14}{|l|}{ Field of study } \\
\hline $\begin{array}{l}\text { Foundation } \\
\text { \&Diploma }\end{array}$ & $75(8)$ & $14(2)$ & $38(4)$ & $23(3)$ & & $0(2)$ & $5(1)$ & $70(8)$ & & $I(0)$ & $I(0)$ & $73(9)$ & \\
\hline Medicine & $|3|(\mid 5)$ & $10(1)$ & $61(7)$ & $60(7)$ & & $5(1)$ & $I I(2)$ & $115(13)$ & & $0(0)$ & $3(0)$ & $128(15)$ & \\
\hline Dentistry & $170(20)$ & $42(5)$ & $74(9)$ & $54(6)$ & $.006^{*}$ & $8(1)$ & $15(2)$ & $147(17)$ & $<.001 *$ & $6(1)$ & $11(1)$ & $153(18)$ & $<.001 *$ \\
\hline Pharmacy & $215(25)$ & $25(3)$ & $116(13)$ & $74(9)$ & & $10(1)$ & $13(12)$ & $192(22)$ & & $4(0)$ & $17(2)$ & $194(22)$ & \\
\hline Physiotherapy & $419(5)$ & $10(1)$ & $18(2)$ & $\mathrm{I}(2)$ & & $3(0)$ & $22(3)$ & $16(2)$ & & $I(0)$ & $10(1)$ & $30(3)$ & \\
\hline Business & $167(19)$ & $33(4)$ & $8(9)$ & $53(6)$ & & $3(0)$ & $16(2)$ & $148(17)$ & & $I(0)$ & $3(0)$ & $163(19)$ & \\
\hline \multicolumn{14}{|l|}{ Year of Study } \\
\hline Year I & $337(29)$ & $70(8)$ & $183(21)$ & $84(10)$ & & $5(1)$ & $25(3)$ & $307(35)$ & & $6(1)$ & $11(1)$ & $320(37)$ & \\
\hline Year 2 & 164(19) & $25(3)$ & $81(9)$ & $58(7)$ & & $2(0)$ & $30(3)$ & $132(15)$ & & $2(0)$ & $11(1)$ & $15 \mid(17)$ & \\
\hline Year 3 & $227(26)$ & $38(4)$ & $106(12)$ & $83(10)$ & $<.001 *$ & $16(1)$ & $23(3)$ & $188(22)$ & $<.001 *$ & $7(1)$ & $14(2)$ & $206(24)$ & $.02 I^{*}$ \\
\hline Year 4 & $|4|(17)$ & $13(2)$ & $54(7)$ & $74(9)$ & & $7(1)$ & $8(1)$ & $126(14)$ & & $I(0)$ & $13(2)$ & $127(14)$ & \\
\hline \multicolumn{14}{|l|}{ Type of Diet } \\
\hline Vegetarian & $34(4)$ & $5(I)$ & $18(2)$ & $I I(2)$ & 0.878 & $4(0)$ & $6(1)$ & $24(3)$ & $.006 *$ & $0(0)$ & $7(1)$ & $27(3)$ & 0.197 \\
\hline Non vegetarian & $835(96)$ & $|4|(16)$ & $406(48)$ & $288(330)$ & & $26(3)$ & $80(9)$ & $729(84)$ & & $16(2)$ & $42(5)$ & $777(89)$ & \\
\hline \multicolumn{14}{|l|}{ Location } \\
\hline Rural & $188(22)$ & $27(3)$ & $98(11)$ & $63(7)$ & & $7(2)$ & $22(2)$ & 159(2) & & $6(1)$ & $13(1)$ & $169(20)$ & 0.197 \\
\hline Urban & $681(79)$ & $119(13)$ & $326(37)$ & $236(27)$ & & $23(2)$ & $64(2)$ & $594(2)$ & & $10(1)$ & $36(4)$ & $635(73)$ & \\
\hline
\end{tabular}

*Chi square test, $\mathrm{P}<.05$ is significant; $\mathrm{P}$; poor, M; moderate, G; good, N; negative, \pm ; neutral, $\mathrm{P}+$; positive 
Table 3 Total knowledge, attitude, and perception and total KAP score distribution

\begin{tabular}{|c|c|c|c|c|c|}
\hline Variables & $\mathbf{N}(\%)$ & Median(IQR) & Poor/Negative & Moderate/Neutral & Good/Positive \\
\hline & & & N (\%) & N (\%) & $\mathrm{N}(\%)$ \\
\hline TKS & & $\mathrm{II}(3)$ & $146(17)$ & $424(49)$ & $299(34)$ \\
\hline TAS & $869(100 \%)$ & $28(3)$ & $30(4)$ & $86(10)$ & $753(87)$ \\
\hline TPS & & $54(10)$ & $16(2)$ & $49(6)$ & $804(93)$ \\
\hline TKAPS & & $92(\mathrm{II})$ & $15(2)$ & $72(8)$ & $782(90)$ \\
\hline
\end{tabular}

TKS; total knowledge score, TAS; total attitude score, TPS; total perception score, TKAPS; total knowledge attitude and perception score

Table 4 Correlation of KAP scores towards FS\&H

\begin{tabular}{llll}
\hline Variables $(\mathbf{N}=869)$ & TAS & TPS & TKAPS \\
\hline TKS & $.176^{* *}$ & $.077^{*}$ & $.36 I^{* *}$ \\
TAS & & $.316^{* *}$ & $.545^{* *}$ \\
TPS & & & $.902^{* *}$
\end{tabular}

Correlation is significant at ${ }^{* *} \mathrm{p}<.0 \mathrm{I}$ level and ${ }^{*} \mathrm{p}<.05$ level,TKS; total knowledge score, TAS; total attitude score, TPS; total perception score

Table 5 Analysis for determinants using linear regression

\begin{tabular}{|c|c|c|c|c|c|c|}
\hline \multirow[t]{2}{*}{ Determinant variable } & \multicolumn{2}{|c|}{ Unstandardized coefficients } & \multicolumn{4}{|c|}{ Standardized coefficients } \\
\hline & B & Std. Error & Beta & OR & p value Sig. & $95 \% \mathrm{Cl}$ for $\mathrm{B}$ \\
\hline Model I(Constant) & 2.459 & 0.169 & - & 14.518 & 0 & $2 . \mid 27$ to $2.79 \mid$ \\
\hline Age & -0.015 & 0.031 & -0.024 & -0.48 & 0.631 & -.077 to .046 \\
\hline Gender & 0.108 & 0.029 & 0.126 & 3.771 & $.000 * *$ & .052 to .164 \\
\hline Race & 0.016 & 0.023 & 0.024 & 0.717 & 0.473 & -.029 to .062 \\
\hline Education & -0.074 & 0.036 & -0.085 & -2.081 & $.038 *$ & -.144 to -.004 \\
\hline Field of study & -0.011 & 0.007 & -0.054 & -1.565 & 0.118 & -.026 to .003 \\
\hline Year of study & -0.011 & 0.016 & -0.036 & -0.739 & 0.46 & -.042 to .019 \\
\hline Type of diet & 0.161 & 0.065 & 0.084 & 2.494 & $.013^{*}$ & .034 to .289 \\
\hline Native & 0.056 & 0.03 & 0.062 & 1.853 & 0.064 & -.003 to. 115 \\
\hline
\end{tabular}

$\mathrm{SE}$, standard error; OR, odds ratio; $\mathrm{Cl}$, confidence interval; significant at $* \mathrm{p}<.05$ and $* * \mathrm{p}<.0 \mathrm{I}$ level

\section{Discussion}

Almost $50 \%$ of the study respondents reported moderate knowledge towards FS\&H. This may contribute to poor understanding of safe food selection and consumption of risky food by negligence, thus higher susceptibility to food poisoning. For example, $58 \%$ of them did not take note of food sstorage methods, $50 \%$ were unaware of common cause of food-borne diseases and $41 \%$, unaware of its long term effects. Negligence on proper food storage, causes and long term consequences of food-borne diseases makes one vulnerable in contaminated food selection and exposes them as easy victims of food related illness. Though the study respondents had $93 \%$ positive attitude, around $22 \%$ do not wash their hands before eating because of untidy wash basins. This attitude compromises the basic hygiene requirement of eating habits which again is a risk factor for food-borne diseases. These findings were different from other studies, which found knowledge and attitudes of young adults towards food safety were at an insufficient level. ${ }^{1}$ The positive attitude could possibly be explained as the study respondents were more educated and mostly belonged to healthcare related educational background than those reported from other studies. Almost 93\% positive perception towards FS\&H encourages better food safety practices among the study respondents in future.

\section{Association of KAP score among socio-demographic factors}

The significant differences in KAP scores among the demographic variables were observed among respondents age, gender, education, course of study, year of study and types of diet categories. Overall, the KAP scores associated with respondents age were found to be good, (27\%) among 21-23 years old, whereas, other studies reported ages 1820 years or above 30 years with good knowledge scores on FS\&H. ${ }^{16}$ In gender category, both genders showed significant association however, females scored better compared to males. This outcome is similar to the study reported by Garayoa et al., (2017). ${ }^{26}$ This could be probably due to the predominant part a female plays in food preparation experience 
and catering custom in the family set-up. No significant association in KAP was found among race category. There were no previous study conducted on the association between ethnicity and KAP. In terms of education, the study observed significant association in attitude and perception, but surprisingly not in knowledge. Based on previous study, as the level of education increases with age, an increase in knowledge was observed, which contradicts with this study. ${ }^{27}$ Though a positive significant association was observed between KAP among the respondents from various field of study, pharmacy students scored highest. This study observes students from healthcare background had much better KAP towards FS\&H compared to non-health related courses. This was proven based on a previous study conducted by Majowiczet.al. (2016). ${ }^{28}$ However, contradicted with a study reported from Malaysia. ${ }^{29}$ A significant association was observed among the year of study. This is also in relation with age and also education of the respondents which can be found in a study conducted by Unklesbay et al., (1998) which suggested strong positive association between the year of study (sophomore graduate) and KAP of respondents. ${ }^{30}$ There were no association observed among types of diet. The association between the location of respondents to KAP; was similar to the study conducted by Teh et al., (2016) which suggested suburban and urban respondents have no association towards KAP for FS\&H. ${ }^{31}$

\section{Ccorrelation between KAP scores towards FS\&H}

Based on this study, it was observed that there were strong positive correlation observed among all the outcome domains studied which is similar to a study reported by Sanlier et al., (2009). However, based on Redmond and Griffith, (2003) knowledge does not necessarily change behavior. ${ }^{[32]}$ According to Ajzen, (2001) and also Crano, (2005), behavior of an individual is in accordance with their intention and, intentions are easily influenced by attitude. ${ }^{13,33}$ Even though, study showed positive attitudes does not necessarily facilitate a change of behavior. According to Ajzen et al., (2001), when new attitudes overrides the habitual attitude, that does not mean it will replace the habitual attitude ${ }^{13}$ However, attitude is still one of the important factors besides knowledge, to prevent the prevalence of food-borne disease outbreak. Besides that, in a study conducted by Sanlier (2009), the need of immediate intervention of education on food safety among the target group in Turkey was emphasized. ${ }^{1} \mathrm{~A}$ statistically significant correlation was found between food hygiene, personal/kitchen hygiene knowledge, food handling practices, food safety attitudes and total scores $(\mathrm{p}<.01)$ that were consistent with our study outcomes. ${ }^{1}$ Overall, this study showed that the respondents had sufficient KAP scores for FS\&H as their total KAP scores against total knowledge, attitude and perception (KAP) scores were found to be moderate and positive contradicting the studies reported earlier. ${ }^{1,13,32,33}$

\section{Determinants among socio-demographic factors}

The respondents of both gender and type of diet were 3.7 times and 2.5 times more likely to practice good FS\&H when compared to other demographical determinants. The findings of this study show that gender influences respondent's attitudes and practices of FS\&H. This is consistent with a previous report which indicated a significant difference in the mean percentage scores for KAP between male and females with the females scoring significantly better than the males on food safety knowledge and practices. ${ }^{34}$ Likewise, Altekruse et al., (1996) reported that unsafe practices were reported more often by men and adults than by women..$^{35}$ Furthermore, this study reveals that the level of education is significantly associated with the knowledge, attitude and practice levels of FS\&H among food handlers. This finding is in agreement with the report of Ansari-Lari et al., who found that knowledge was significantly higher among food handlers with a higher educational level. ${ }^{36}$ Similarly, Abdul-Mutalib et al., recommended that continuous education would strengthen knowledge of food hygiene. ${ }^{37}$ Improving college students' or young adults' attitudes about FS\&H may be the first step towards influencing their food safety behaviours.

\section{Conclusion}

Through continuous education and campaigns related to FS\&H, better awareness can be created to help maintain a safe and hygienic food habit. The food borne disease outbreak that is prevalent in the country can be subsequently reduced if each and every one of us are responsible enough to take initiatives, rather than pinpointing fingers.

\section{Study limitation}

The results attained may not be representative of all the students for different ages and academic levels as the study was conducted in only one university. Furthermore, the study was self-reported, which might have been biased as they do not self-reflect their actions while answering.

However, all attempts were made to minimize such errors through appropriate research design and methodology.

\section{Acknowledgements}

We are grateful to the management of AIMST University, Malaysia for their permission, support and encouragement extended for carrying out this study and the study participants for their time and cooperation for this study.

\section{Author contributions}

All authors contributed toward data collection, data entry, analysis, drafting and critically revising the paper and agree to be accountable for all aspects of the work.

\section{Disclosure}

The authors declare no conflicts of interest in this work.

\section{Supplementary publications}

The author disclosure that there is a supplementary manuscript submitted for publications elsewhere with the source data and overlapping methods. However, the objective and scope of the manuscript has no overlapping information.

\section{Conflict of interest}

Author declares that there is no conflict of interest

\section{References}

1. Sanlier N, Konaklioglu E. Food safety knowledge, attitude and food handling practices of students. British Food Journal. 2012;114(4):469-480.

2. Newell DG, Koopmans M, Verhoef L, et al. Food-borne diseases-the challenges of 20 years ago still persist while new ones continue to emerge. International journal of food microbiology. 2010;139:S3-S15.

3. Osaili TM, Obeidat BA, Jamous DO, et al. Food safety knowledge and practices among college female students in north of Jordan. Food Control. 2011;22(2):269-276. 
4. World Health Organization (WHO). World health report: global public health threats in the 21st century. 2007.

5. Wilcock A, Pun M, Khanona J, et al. Consumer attitudes, knowledge and behaviour: a review of food safety issues. Trends in Food Science \& Technology. 2004;15(2):56-66

6. Food hygiene [Internet]. World Health Organization. 2018.

7. Byrd Bredbenner C, Abbot JM, Quick V. Food safety knowledge and beliefs of middle school children: implications for food safety educators. Journal of Food Science Education. 2010;9(1):19-30.

8. Zimmerman M, San Francisco, Jossey Bass, et al. Book Reviews: Health Behavior and Health Education: Theory, Research, and Practice 1990. Health Education Quarterly. 1991;18(4):520-523.

9. Samuel MC, Vugia DJ, Koehler KM, et al. Consumption of risky foods among adults at high risk for severe foodborne diseases: room for improved targeted prevention messages. Journal of food safety. 2007;27(2):219-232.

10. Lazou T, Georgiadis M, Pentieva K, et al. Food safety knowledge and foodhandling practices of Greek university students: A questionnaire-based survey. Food Control. 2012;28(2):400-411.

11. Hassan HF, Dimassi H. Food safety and handling knowledge and practices of Lebanese university students. Food Control. 2014;40:127-133.

12. Mullan BA, Wong C, Kothe EJ. Predicting adolescents' safe food handling using an extended theory of planned behavior. Food Control. 2013;31(2):454-460.

13. Ajzen I. Perceived behavioral control, self-efficacy, locus of control, and the theory of planned behavior 1. Journal of applied social psychology. 2002;32(4):665-683.

14. AIMST University | Ranking \& Review [Internet]. 4icu.org. 2018

15. Sample Size Calculator by Raosoft, Inc. [Internet]. Raosoft.com. 2018.

16. Low WY, Jani R, Halim HA, et al. Determinants of food hygiene knowledge among youths: a cross-sectional online study. Food Control. 2016;59:88-93.

17. Akabanda F, Hlortsi EH, Owusu Kwarteng J. Food safety knowledge, attitudes and practices of institutional food-handlers in Ghana. BMC public health. 2017;17(1):40

18. Ferk CC, Calder BL, Camire ME. Assessing the food safety knowledge of university of Maine students. Journal of Food Science Education. 2016;15(1):14-22.

19. Kubde SR, Pattankar J, Kokiwar PR. Knowledge and food hygiene practices among food handlers in food establishments. Int $J$ Community Med Public Health. 2016;3(1):251-256.

20. George D, Mallery P. SPSS for Windows step by step: A simple guide and reference. 11.0 update. 2003.

21. Henson RK. Understanding internal consistency reliability estimates: A conceptual primer on coefficient alpha. Measurement and evaluation in counseling and development. 2001;34(3):177-189.
22. Kaliyaperumal KI. Guideline for conducting a knowledge, attitude and practice (KAP) study. AECS illumination. 2004;4(1):7-9.

23. Bhagavathula AS, Elnour AA, Jamshed SQ, et al. Health professionals knowledge, attitudes and practices about pharmacovigilance in India: A systematic review and meta-analysis. PloS one. 2016;11(3):e152221.

24. Nahida A. Knowledge Attitude and Practice on Dengue Fever (Doctoral dissertation, Thesis for Masters in Public Health).

25. John J. The knowledge, attitude, practice and perceived barriers towards screening for premalignant cervical lesions among women aged 18years and above, in Songea urban, Ruvuma.

26. Garayoa R, Cordoba M, Sanchez Villegas A, et al. Relationship between consumer food safety knowledge and reported behavior among students from health sciences in one region of Spain. Journal of Food Protection. 2005;88(12):2631-2636

27. Courtney SM, Majowicz SE, Dubin JA. Food safety knowledge of undergraduate students at a Canadian university: results of an online survey. BMC public health. 2016;16(1):1147.

28. Majowicz SE, Hammond D, Dubin JA, et al. A longitudinal evaluation of food safety knowledge and attitudes among Ontario high school students following a food handler training program. Food Control. 2017;76:108116.

29. Moy FM, Alias AA, Jani R, et al. Determinants of self-reported food safety practices among youths: A cross-sectional online study in Kuala Lumpur, Malaysia. British Food Journal. 2018;120(4):891-900.

30. Unklesbay NA, Sneed J, Toma R. College students' attitudes, practices, and knowledge of food safety. Journal of Food Protection. 1998;61(9):11751180 .

31. Teh NS, Ab Hamid MR, Asmawi UM, et al. Food Hygiene's Knowledge, Attitudes and Practices between Urban and Suburban Adolescents Procedia-Social and Behavioral Sciences. 2016;234:36-44.

32. Redmond EC, Griffith CJ. Consumer food handling in the home: a review of food safety studies. Journal of food protection. 2003;66(1):130-161.

33. Crano WD, Prislin R. Attitudes and persuasion. Annu Rev Psychol. 2006;57:345-374.

34. Sharif L, Al Malki T. Knowledge, attitude and practice of Taif University students on food poisoning. Food Control. 2010;21(1):55-60.

35. Altekruse SF, Street DA, Fein SB, et al. Consumer knowledge of foodborne microbial hazards and food-handling practices. Journal of food protection. 1996;59(3):287-294.

36. Ansari Lari M, Soodbakhsh S, Lakzadeh L. Knowledge, attitudes and practices of workers on food hygienic practices in meat processing plants in Fars, Iran. Food control. 2010;21(3):260-263.

37. Abdul Mutalib NA, Abdul Rashid MF, Mustafa S, et al. Knowledge, attitude and practices regarding food hygiene and sanitation of food handlers in Kuala Pilah, Malaysia. Food Control. 2012;27(2):289-293. 